\title{
The organization and administration of intensive patient care
}

\author{
E. SHer Wood Jones \\ Intensive Care Unit and Clinical Pharmacology Unit (University of Liverpool), \\ Whiston Hospital, Prescot
}

The more desperately ill a patient is, the more needed is a top-flight specialist in internal medicine, that is, one who can use his hands at three o'clock in the morning.

LASSEN, 1965

BEFORE giving definitions of the labels which adorn my subject, it is salutary to put the whole subject of intensive patient care into perspective. This can be done by referring to Fig. 1 which is based on a

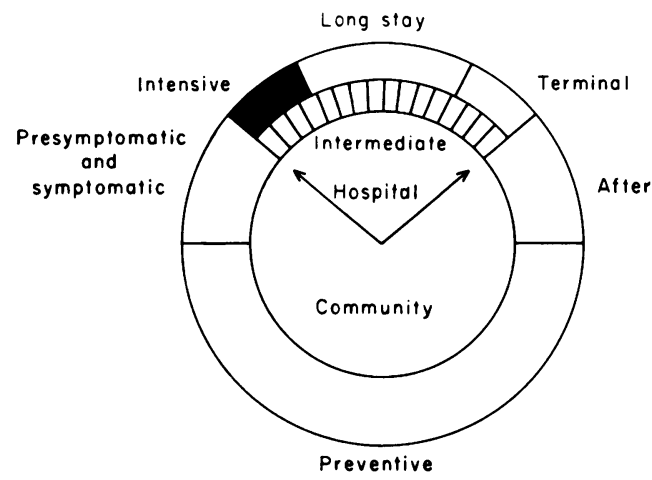

Fig. 1.

diagram by Logan (1965). It will be seen that hospital patient care has two large components of intermediate (including self care) and long-stay care and two small areas of intensive and terminal care; intensive patient care is an important but small fraction of hospital care.

\section{Definitions}

Intensive nursing care is as old as organized nursing. In relation to the adult with a severe illness it means the detailed and enlightened care of the whole patient; the appropriate rest and movement, the feeding, care of the skin and hygiene of excreta. Whether the illness is primarily 'mental' or not does not allow neglect of psychological care by the nurse. This is a theme to be expanded later, but it may be stated now that one of the most rewarding results of working in an intensive care unit is to witness and participate in the close discussion, explanation and encouragement of the individual patient.

Intensive Therapy is a convenient label to apply to the activities of a therapeutic team. It is likely that most of the therapy will be executed by the nurse. The nurse is, and will remain, the front-line therapist in acute illness and the most important administrator of drugs, infusions, inspired gases and food. In addition, she must be conversant with physiotherapy and with the mechanical aids-for example, the respirator, artificial kidney or cardiac pacemaker. If we leave aside the minute to minute therapeutic requirements of resuscitation, then the plan for the intensive therapy of any acute illness is usually well defined; for example, acute renal failure (Merrill, 1965) and status asthmaticus (Grant, 1966). There are invariably some common denominators which can be planned in advance; important ones are oxygen therapy, prevention or treatment of infection and metabolic care.

\section{Essentials of intensive therapy}

The five essential needs of intensive patient care are listed in Table 1. Of fundamental importance is

TABLE 1

Essentials of intensive patient care (in order of significance)

1. Permanent nursing complement specifically trained and giving continuous service

2. Readily available medical and scientific complement $1+2=$ Therapeutic team

3. Standardized techniques of investigation and treatment

4. An 'area', 'facility' or 'unit'

5. A revised psychology of patient care

the first requirement, namely a high nurse-to-patient ratio of specifically trained nurses. These nurses give intensive patient care, measure and record and carry out most of the intensive therapy.

The constitution of the medical staffing was clearly summarized by Finn et al. (1960) as follows: 'An adequate amount of specialized and experienced medical manpower must be brought to bear on any acute problem soon after admission. The time of the day or night should not influence the available manpower. The management of an acute emergency may demand the resources of several specialities.' 
The nurse/doctor team is aided by a clinical physiologist, biochemist or pharmacologist. The doctors and scientists need technical assistants and laboratory facilities adjoining the intensive care unit. In addition to this full-time staff, considerable part-time help is required from the X-ray and physiotherapy departments and from the hospital laboratory.

The third essential of intensive therapy is to standardize the methods of investigation and treatment. The symposium papers on acute renal failure and crushing injuries of the chest have illustrated the need for a plan of systematic investigation so that urinary tract obstruction or bronchial tears, for example, are not overlooked. Similarly, treatment

\section{TABLE 2}

Units for intensive patient care

\begin{tabular}{l}
\hline Regional units \\
Neonatal \\
Surgery \\
Paediatric \\
Medicine \\
Surgery \\
Renal \\
Respiratory \\
Thoracic surgery \\
Neurosurgery \\
Burns \\
Neuropsychiatric \\
Local hospital units \\
Neonatal-within a maternity unit \\
General internal medicine \\
Coronary \\
General surgery \\
Accident \\
Related therapeutic services \\
Recovery ward \\
Resuscitation \\
Cardiorespiratory \\
Flying squad \\
Maternity \\
Accident \\
\end{tabular}

must, as far as is possible, be pre-planned. This principle applies both to the materials and to their use. A few examples will help to illustrate these points. In each treatment room of our intensive care unit are stored materials for one or more treatments, say tracheostomy care, and the stocks are maintained from a C.S.S.D. The feeding of acutely ill patients can be reduced to one of three schemes (Jones \& Peaston, 1966) and when this is done the materials will always be to hand and the nurse familiar with each technique. Clearly the equipment must be adapted to the patient or disease. Thus, IPPV or intravenous feeding of the neonate required quite different apparatus from those described in this symposium (Rickham, 1962). Following cardiothoracic surgery, the water and electrolyte needs can usually be predicted and the infusions therefore standardized (Braimbridge \& Ghadiali, 1965). The extensive use of IPPV during and after cardiothoracic surgery has helped to make this a routine treatment. The workload of the technique is therefore reduced, the complications become fewer, and the applications wider (Norlander et al., 1961).

An intensive care unit is an area within which patients receive intensive care and therapy. Such a के unit may serve a single hospital (Crocket \& Barr, $\overrightarrow{0}$ 1965; Fairley, 1961; Finn et al., 1966), group of $\overrightarrow{ }$ hospitals or a region. During the past 10 years the label intensive care unit has been a talking point in British hospitals and there has been considerable confusion relating to the function of such units. There is no need for confused thinking if we recall the varied functions carried out in intensive care units. Such functions are listed in Table 2. It will be seen that intensive care units are of many years' standing and carry out very varied types of therapy. Examination of the demands on each speciality will lead to the following conclusions. Firstly, about half of the units will serve the hospitals of an entire region (Parsons \& McCracken, 1959; Forshall \& Rickham, 1960). The place of the coronary care unit $\mathscr{\sigma}$ must await the results from the experimental units already established (Brown et al., 1963; Schillingford \& Thomas, 1964). The second deduction which seems logical is that intensive care of the adult medical or surgical patient is best carried out in a unit or units established in all district hospitals. By this is meant the segregation of ill patients which forms an integral part of progressive patient care (Beardsley, Bowen \& Capalbo, 1956; Elements of Progressive Patient Care, 1959; Lockward \& Thomas, 1960; Safar et al., 1961). Such a unit would fulfil the true aim of intensive patient care and in most regions is probably the only justification for the establishment of an intensive care unit in a district hospital. Of course, it might be that the regional burns unit (Evans, 1957) or neonatal surgical unit (Forshall \& Rickham, 1960) was sited at a district 9 hospital, but this would not remove the need for progressive patient care within the medical and surgical units.

Many British intensive care units have evolved from treatment carried out in 'side wards', 'private rooms' or a recovery ward. We can all readily recall w our house-officer experiences of resuscitation and $\widetilde{Z}$ intensive therapy carried out in a Nightingale ward $\bullet$ in the depths of the night. Work was made difficult $\mathbb{D}$ by the simplest shortcomings-delay in getting? equipment dispersed throughout a hospital, lack of $T$ immediate laboratory and X-ray services, and perhaps most depressing of all, the failure of communication between nurse and nurse, and doctor and $\stackrel{\square}{\square}$ nurse which determines the continuity of measurement and treatment. The isolated room was therefore 
an obvious step forward, especially during the night, in that noise was no longer disturbing to other patients and lighting could be adjusted to the individual needs. There was more space to work and this sometimes allowed access all round the bed. The isolation of the seriously ill patient meant that more nurses were needed, or, to use the old phrase, the patient had to be 'specialled'. The problem could only be solved by obtaining a permanent team of nurses specifically trained to do the job. From a study of the literature and from personal experience it seems that two environments are still required in which to carry out intensive patient care and therapy. That is, in addition to the development of a side ward into a treatment room, a second form of accommodation is desirable. The two types of accommodation provide for the initial care of either distinct types of illness-for example, acute cardiac infarction contrasted with multiple injuries-or grades of severity of the same illness, and has therefore the other advantage of enabling progressive care to be carried out within the confines of the intensive care unit; this design can also be more readily adapted to changing needs (Lancet, 1952). The second type of accommodation is an adaptation of an up-to-date ward interior. Groups of beds are sited within viewing distance of a nurses' station. In addition to visual observation, the provision of transmitted speech or monitoring is easily installed. A revised psychology of patient care means that the nurse takes on new and greater responsibilities for patient care and treatment and that a team of consultants rather than an individual specialist is responsible for the overall therapeutic plan. The psychology of the nurse-doctor team may be classified as that of a primary group (Sprott, 1958) and the interpersonal relationships are described below under 'Results of intensive therapy'.

\section{Bases of intensive therapy}

Experience in the teaching of postgraduate nurses attending courses in intensive therapy has supported my belief that there is much to be gained by a deliberately over-simplified biochemical and mechanical approach to intensive therapy. Such an interpretation helps one to take an overall view of the treatment and maintains a balanced perspective of the value of the varied forms of therapy available. The cell injured by bacterial toxin or ischaemia, for example, will have an improved chance of recovery if the extra-cellular fluid is maintained in a physiological state. Indeed, most intensive therapy aims at restoring the volumes and composition of the body fluids. For specific research projects on acute illness, the sizes of the body fluid compartments have been conveniently measured by means of isotopes, but for day-to-day practice the composition of the blood or plasma is usually determined and we must constantly remind ourselves that this can give little information about the larger body fluid compartments (Black, 1964).

Intensive therapy depends on a variety of treatment and the preceding papers have given detailed information on each of the four groups shown in Table 3. A patient rendered helpless by an acute

TABLE 3

Bases of intensive therapy

illness, trauma or surgery may require several forms of therapy and if these are continuous then the demands on the therapeutic team will be large.

\section{Natural history of the diseases requiring intensive therapy}

If trauma and acute renal failure are excluded then it must be admitted that the diseases requiring intensive therapy are chronic, usually progressive and their course is punctuated by acute illnesses which may threaten life and which may need intensive therapy. The same may be said for cardio-

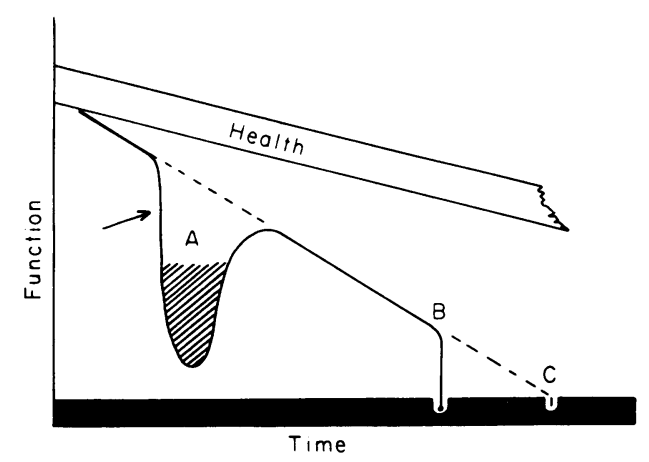

Fig. 2

A. Metabolic

Food, drugs, water and electrolytes via GIT

Blood transfusion

resins or dialysis

B. Respiratory

Inspired gases modified in composition or pressure

C. Mechanical

Bronchial lavage

Scribner shunt

Cough machines

siotherapy

Cardioversion

Pacing

Defibrillation 
thoracic surgery in the adult, and the problem of poisoning may be recurrent. This simple truth has very important bearings on: (1) the selection of patients for intensive therapy, (2) the therapeutic plan for each condition, and (3) the administration of a unit.

The natural history of a chronic condition is shown in Fig. 2. The loss of function over time due to a chronic disease such as bronchitis, coronary artery disease, asthma or pyelonephritis is more rapid than that due to ageing alone. The course of the illness is interrupted by two acute episodes (A and B), the second (B) killing the patient some time before that predicted for the chronic disease (C). Let us assume that our patient had chronic bronchitis and emphysema and that the first episode required IPPV and tracheostomy (cross-hatched area). The decision to select the patient was easily reached because of the gravity of the clinical situation and because of the relatively moderate disability prior to the acute illness. Indeed, the chances of success of this method of treatment are best when applied to this situation (Munck, Kristensen \& Lassen, 1961). When the second acute illness occurred, our patient was a cripple and intensive therapy was not recommended. A detailed knowledge of the natural history of the disease was therefore essential to the treatment of our patient. Perhaps if antibiotics, aerosols, controlled oxygen and chest physiotherapy had been given early (arrow) in the acute episode (A) then intensive therapy would not have been necessary!

\section{Results of intensive therapy}

The activities of the therapeutic team serving a district hospital or entire region should achieve five objectives:

(a) Mortality and morbidity will be lowered both of specific diseases such as acute cardiac infarction and of the wide variety of conditions admitted to the unit of a district hospital. How is this result to be judged? Overall mortality figures for intensive care units are of little value but those for specific problems give some indication of the efficiency of the team, although these results may be adversely affected by delay in referral. At Whiston, we have found this to be so for abdominal surgery complicated by respiratory or renal failure or both. In such patients there is a stage beyond which the changes in the body fluids cannot be reversed, and the activities of the therapeutic team are bound to fail. In the traumatic field, mortality figures are seriously influenced by irreversible damage to the central nervous system. Thus the mortality from severe crushing injuries to the chest requiring respirator treatment should be about $25 \%$, but if combined with serious head injury the figure may be double.

Some generalizations are given about death rates of renal failure, cardiac infarction and thoracico surgery in the papers of this symposium. The $c$ mortality from poisoning, acute gastro-intestinal bleeding and diabetic coma should be below $10 \% .+\overrightarrow{0}$

(b) Regional and district intensive care unitse provide 'the organization of facilities, services and staff around the medical and nursing needs of the

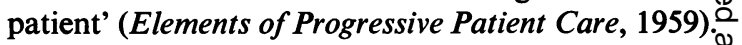
Regional units for burns, renal failure, neonatafs surgery, neuro-surgery, thoracic surgery will serves populations of 2-4 million. In the district hospital, the intensive care unit is likely to need $1-2 \%$ of the्ल total short-stay beds.

(c) The intensive care unit is a suitable setting in which a therapeutic plan can be evolved or evalu ated. The justification for this statement is that the clinical observations are certain to be more accurateot and reliable than those made in other parts of the hospital. Secondly, the standards of observation of therapy are largely independent of the time of theo day or night. Thirdly, the equipment needed fordiagnosis, treatment and for the control of that treatment are readily available. The standards of. therapy are raised by the participation of severalspecialists and by the experience of the specialistso themselves (Holmdahl, 1962). The patient is less likely to be de-humanized by the doctor than in other parts of the hospital. This should spur thes doctor to greater efforts on behalf of the individuab patient. Personally, however, I feel that although thiso fact is important it is not such a powerful motivatoo as the challenge of the disease process itself. $I_{\vec{b}} \vec{b}$ many intensive care situations the patient will noB recover unless some advanced form of therapy is quickly commenced and carefully performed. There can, therefore, be no chance of recovery without active and sometimes continuous doctoring. The situation is similar to the surgery of trauma or the acute abdomen except that the time scale differs Unless the team can employ or develop suitable treat ment, the battle is lost. Unless it becomes clear during treatment that the condition is not amenable to the therapy available, then each patient dying in the unit represents a defeat of the team.

(d) Personal experience over 4 years has led me tơ conclude that intensive therapy provides a challenge to nursing. The nurse soon comes to appreciate that nursing care alone will not guarantee recovery and $w$ that she must advance her knowledge and accep? greater responsibilities. The nurse must be the chies observer and therapist but cannot become so with out an understanding of the significance of her ${ }^{\text {? }}$ observations or the basis of the therapy. This learn $-\frac{T}{C}$ ing can only come from the medical and scientific members of the team. The learning is a continuous process, depends on direct verbal communication $\mathbb{D}$ between doctor and nurse and involves tuition ore each patient. 'Learning is also a feed-back process 
and it consists essentially of seeing the effect of one's own behaviour. Unless one receives intelligible responses to, or clarifying information about, what one is trying to do, it is impossible to learn' (Revans, 1964). Now, it has been established that the quality or quantity of the communication system may influence the efficiency of the doctor-nurse team (Hetherington, Miller \& Neville, 1964). It is therefore necessary to bear in mind the factors which may inhibit the free and rapid communication necessary for the working of the therapeutic team. There are three main barriers to communication in this setting. The status (or hierarchical) barrier operates in one or more of the three groups of the team and between each group (Hetherington et al., 1964). Thus a nurse may observe some new clinical sign in her patient but refrain from informing her superior or a doctor in the team. This barrier is readily bridged if the nurse becomes the chief observer when it is then her responsibility to record and communicate clinical signs. The next barrier is one of language. The therapy of the team depends on applied physiology, biochemistry and pharmacology. For teaching, special efforts must be made to simplify the descriptions of measurement and therapy. The meaning and interpretation of $\mathrm{pH}, \mathrm{PCO}_{2}$ and bicarbonate of blood is an example. If a change in one or more of these three variables is described in relation to individual patients and their treatment and cumbersome terminology avoided, then the nurse will soon come to appreciate their significance; after all, their clinical use was fully understood in 1928 (Henderson, 1928)! The third impediment to the functioning of the team is the demarcation or 'closed-shop' barrier. This problem is especially prominent in British medicine which is so diploma-conscious. Two examples will serve to illustrate the problem. The team may disagree on some aspects of the therapeutic plan such as how to control pulmonary ventilation. If one member of the team resents free discussion of the problem because he feels that he alone is qualified to decide, then the others in the team may also become closed-shop minded. It then becomes very difficult to co-ordinate the specialities concerned and design a therapeutic plan. Similarly, in nursing, a qualified nurse may resent the help given by technicians during haemodialysis because she feels that this treatment is exclusively a nursing responsibility. It follows that members of the team must learn to delegate responsibility and not imagine themselves to be indispensable.

(e) The last, but by no means the least, advantage of the intensive care unit is that it can provide a focal point for postgraduate education. There is a continuous pooling of nursing, medical and scientific information. Treatment is more likely to be controlled by repeated measurement which helps to assess the results. During intensive therapy it is inevitable to ask the question: 'Could this disease have been given better treatment at an earlier stage?' The doctors attached to the unit are thus stimulated to improve their standards of treatment of acute conditions admitted to other wards. This feed-back of knowledge has certainly helped to reduce both the incidence and mortality of acute renal failure and status asthmaticus. To reduce deaths from asthma in our hospital, a plan of early treatment was established (Riding, 1966) which usually avoided the need for IPPV with oxygen and bronchial lavage. Finally, the intensive care unit enables junior hospital staff to study the principles of clinical science (Lewis, 1939) and to carry out and publish their researches. The latter is a small reward for the large demands required of them.

\section{Organization of intensive patient care in the district hospital}

The intensive care unit of a district general hospital provides a regular service to the medical and surgical units and an occasional admission from the accident, psychiatric, obstetric and other departments. The beds required for intensive therapy are about $1-2 \%$ of the total short-stay beds for internal medicine and surgery. In a hospital with a very large number of short-stay beds it may be advantageous to establish separate units for internal medicine and surgery. Although most surgical admissions to the intensive care unit come from the recovery ward, the former is not a substitute for the latter. The general intensive care unit of an existing hospital (Hall, 1966; Hothersall, 1966; Nursing Times, 1964, 1966; Saltor, 1966; Bateman, 1966) cannot be sited with the same advantage as a unit planned with a new hospital. There should be easy transport of patients from the casualty, admission room, accident unit, operating theatres and recovery wards; the medical and surgical beds take second priority. Intensive care is at one end of a spectrum of hospital care, the other end is self-care. A self-care unit is like a hostel or hotel and is used for patients who need long diagnostic tests or closely supervised treatment, e.g. diabetes mellitus or hypertension. A day ward is a variant of the self-care ward (Bateman, 1966). Additional patients are transferred to self-care or intermediate care when their disabilities allow. The nursing requirements are minimal and involve clinical observations and the giving of injections. The self-care unit appeals to me as a logical component of progressive patient care but I have no personal experiences. Progressive patient care has now been widely adopted and favourably received in hospitals in the United States. The self-care unit avoids the misuse of nursing, provides the environment suited to the recovery stage of a severe illness and (in the United States) more than halves the patient bill (Golin, 1958; Mod. Hosp., 1966). 


\section{Administration}

Intensive patient care can only be administered by a team composed of doctor-nurse-administrator. This team is required to establish intensive patient care by taking a census of the beds for a region or district, to site and design a suitable unit and then to staff and equip this unit. The intensive care unit is an additional department of the hospital and therefore requires a departmental nurse-in-charge to organize nurse duties and training.

Intensive therapy is given by a team consisting of nurse-doctor-scientist. 'The need for specialized help should compel the staffs of modern hospitals to work in teams so that expert advice is available on every facet of the illness of the individual. No single doctor can undertake everything and the more the patients are considered by able young men and their more experienced elders, the more likely are the conclusions to be valid and based on a competent assessment of all available evidence' (McMichael, 1964). The activities of the team must be co-ordinated by a chairman. The choice of a chairman will depend on the function of the particular unit and he might therefore be a cardiologist, thoracic surgeon, neurologist or renal physician. This chairman would give guidance on the selection of patients for intensive therapy and for this he needs a detailed knowledge of the natural history of the problems to be treated.

The recovery ward is a vital part of intensive therapy of the surgical patient. The observations and therapy in the recovery ward are made by the team nurse-surgeon-anaesthetist. Since most of the problems are respiratory it is logical that the anaesthetist should be chairman of therapy (Saklad, 1960).

\section{References}

Bateman, P. (1966) Day Ward at the Royal Southern Hospital, Liverpool. Nursing Times, 62, 81 .

Beardsley, J.M., Bowen, J.R. \& Capalbo, C.J. (1956) Centralised treatment for seriously ill surgical patients. $J$. Amer. med. Ass. 162, 544.

BLACK, D.A.K. (1964) Essentials of Fluid Balance, 3rd edn, p. 127. Blackwell Scientific Publications, Oxford.

Braimbridge, M.V. \& Ghadiali, P.E. (1965) Post-operative Cardiac Care, p. 23. Blackwell Scientific Publications, Oxford.

Brown, K.W.G., Macmillan, R.L., Forbath, N., MelGRANO, F. \& SCOTT, J.W. (1963) Coronary unit. An intensive-care centre for acute myocardial infarction. Lancet, ii, 349.

Crocket, G.S. \& Barr, A. (1965) An intensive-care unit: two years' experience in a provincial hospital. Brit. med. J. ii, 1173.

Evans, A.J. (1957) Experiences of a burns unit. Brit. med.J. ii, 547.

Elements of Progressive Patient Care (1959) U.S. Department of Health, Education and Welfare, Washington.

Fairley, H.B. (1961) The Toronto General Hospital Respiratory Unit. Anaesthesia, 16, 267.
FinN, R., HaggaRT, B.G., White, W.F. \& Jones, R.H.T§ (1966) A General Intensive Therapy Unit. Brit. med. JC. i, 39.

FORSHALl, I. \& RickhaM, P.P. (1960) Experience of $\underset{\overrightarrow{3}}{\overrightarrow{7}}$ neonatal surgical unit. Lancet, ii, 751.

Golin, M. (1958) At last-a hospital to fit doctor-patien needs. J. Amer. med. Ass. 166, 2180.

GranT, I.W.B. (1966) Status asthmaticus. Nursing Times, $62,868$. HALL, R. (1966) Intensive Care Unit at Harefield Hospital
Nursing Times, 62, 1392 .

Hetherington, R.R., Miller, D.H. \& NeVille, J.G. (1964) Introduction to Psychology for Medical Students, chap. 20: Heinemann, London.

HENDERSON, L.J. (1928) Blood. A Study in General Physiology Yale University Press.

Holmdahl, M.H. (1962) The respiratory care unit. Anaes thesiology, 23, 559.

Hothersall, T. (1966) Intensive Care Unit. Nursing Times $\vec{\omega}$ 62, 760.

Jones, E.S. \& Peaston, M.J.T. (1966) Metabolic care duringe acute illness. Practitioner, 196, 271.

Lancet (1964) A unit for intensive care. Lancet, i, 657.

LASSEN, H.C.A. (1965) Discussion of The Management of Respiratory Failure in Chronic Obstructive Lung Disease by R.M. Cherniack. Ann. N.Y. Acad. Sci. 121, 957.

LEWIS, T. (1939) Research in Medicine and other Addresses, $\rightarrow$ 2nd edn. Lewis, London.

Lockward, H.J. \& Thoms, E.J. (1960) Progressive patiene. care. J. Amer. med. Ass. 172, 132.

Logan, R.F.L. (1964) Problems and Progress in Medicab Care (Ed. by G. McLachlan), p. 21, Fig. 1. Oxford.

McMichael, J. (1964) An interesting case in Ward 6. Lancet i, 825.

MerRiLl, J.P. (1965) The Treatment of Renal Failure, 2nd edn. Heinemann, London. Mod. Hosp. (1966) Hospital is Expanding its PPC Planning $\frac{\text { 10 }}{\mathrm{Q}}$
106, 99.

MunCK, O, KRISTEnSen, H.S. \& LASSen, H.C.A. (1961) Mechanical ventilation for acute respiratory failure in diffuse chronic lung disease. Lancet, i, 66.

Norlander, O.P., BJork, V.O., Crafoord, C., Friberg O., Holmdahl, M., Swensson, A. \& Widman, B. (1961) Controlled ventilation in medical practice. Anaesthesia, 16, 285.

Nursing Times (1964) Intensive Care Ward. The Generab Infirmary at Leeds. Nursing Times, 60, 624.

Nursing Times (1966) Acute Care Ward, Charing Cross Hos pital, London. Nursing Times, 62, 1126.

Parsons, F.M. \& McCracken, B.H. (1959) Artificial kid ney. Brit. med. J. i, 740.

Revans, R.W. (1964) Problems and Progress in Medica Care (Ed. by G. McLachlan), p. 66. Oxford.

Ricкнам, P.P. (1962) Pre-operative and Post-operative. Care of Infants in Pediatric Surgery (Ed. by Benson et al.) Year Book Medical Publishers. RIDING, W.D. (1966) The management of the severe asth $N$ N
matic attack. Practitioner, 197, 659.

Safar, P., Dekornfeld, T.J., Pearson, J.W. \& Redding, J.S. (1961) The Intensive Care Unit. Anaesthesia, 16, 275

SAKLAD, M. (1960) Responsibility of the anesthesiologist? J. Amer. med. Ass. 174, 2020.

Saltor, M. (1966) Intensive Therapy Unit, The London Hospital. Nursing Times, 62, 1457.

Shillingford, J.P. \& ThOMAs, M. (1965) Intensive care and resuscitation in heart disease. The Intensive Care and Investigation of Acute Myocardial Infarction, p. $29 \stackrel{\mathbb{Q}}{\mathrm{D}}$ Chest and Heart Association.

SPROTT, W.J.H. (1958) Human Groups. Penguin Books $\widetilde{\sigma}$ Harmondsworth. 